\title{
Availability Prediction Methods for Terrestrial Free-Space- Optical Link Under Tropical Climate
}

\author{
Ahmed Basahel, Md. Rafiqul Islam, Mohamed Habaebi, Suriza Ahmad
}

Electrical \& Computer Engineering Department, International Islamic University Malaysia

\begin{tabular}{l}
\hline \hline Article Info \\
\hline Article history: \\
Received Jan 11, 2018 \\
Revised Mar 8, 2018 \\
Accepted Mar 22, 2018 \\
\hline
\end{tabular}

\section{Keywords:}

Availability

Free Space Optics

Atmospheric Attenuation

FSO Link Budget

\begin{abstract}
Free-space optical (FSO) links provide high speed point-to-point wireless communication, but its availability can easily be affected by weather conditions. In heavy rainfall regions, FSO links are relatively sensitive to rain. Availability prediction of FSO is indispensable part, especially in tropical areas. In this paper, methods to predict FSO link availability are presented. The overall performance of FSO link is described in terms of the availability that can be achieved over anticipated link distance. The availability prediction methods demonstrated for an FSO link ranges up to 5 $\mathrm{km}$. The availability prediction methods are based on long-term statistics of atmospheric attenuations and FSO link budget under tropical climate condition. In tropical regions, for a terrestrial FSO link, carrier class availability can be achieved over a few hundred meters only; whereas enterprise class availability can be achieved over a few kilometers link distances.
\end{abstract}

Copyright $\odot 2018$ Institute of Advanced Engineering and Science. All rights reserved.

\section{Corresponding Author:}

Md. Rafiqul Islam,

Electrical \& Computer Engineering Department,

International Islamic University Malaysia,

Jalan Gombak, 53100 kuala Lumpur, Malaysia, Tel: +603 6196 4530/ Fax: +60361964488.

Email: rafiq@iium.edu.my

\section{INTRODUCTION}

FSO is a wireless technology that uses light as a medium of transmission between a pair of transceivers as shown in Figure 1. FSO systems are categorized under optical wireless and consider an emerging high speed point-to-point broadband technology [1]. FSO systems can be used for terrestrial applications such as: inter building connections, backhaul for cellular systems, high quality video surveillance in a city and redundant links for fiber optic. It can be deployed over a few kilometers link distances. Over the years, FSO technology has gained acceptance in enterprise campus network [1]. FSO provides high bandwidth with fast installation time compare with fiber optic [2]. It is also, to date, have free licensing of frequency and high secure compare with radio.

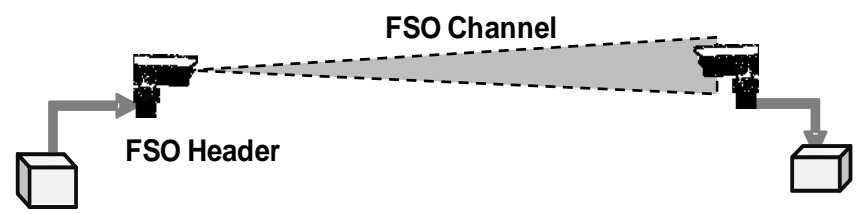

Figure 1. FSO system's components 
Particles suspended in the air due to different weather phenomena such as fog, rain and haze are usually interacting with the photons of optical wavelength causing scattering of the optical signal [3]. Scattering of the optical signal cause attenuation, thereby reducing the overall availability of FSO system. In addition to the weather impact, the FSO channel is affected by scintillation due to atmospheric turbulence [4]. The effect of scintillation can be compensated by using diversity schemes [5]. In tropical regions, the effect of scintillation is almost negligible due to low refractive index structure of turbulence [6]. Moreover, multiuser diversity can improve the capacity performance of FSO channel over strong turbulence [7]. Pointing errors due to misalignment between the two FSO installed headers can also cause additional loss [8]. Practically, this loss can be incurred over more than $3 \mathrm{~km}$ FSO link distance [9]. Pointing loss is related to the design of the FSO equipment and can be accomplished by installing FSO headers on solid parts of the building with active auto-tracking system. The auto-tracking system normally uses close loop feedback control mechanism to keep the receive beam on target [9]. These external and internal parameters can affect the performance and link availability of FSO link. Practically, link availability is used to measure the quality of service of a communication system. Therefore, it is important to explain the availability concept and how it will be predicted. The availability can be defined as the time that a link is in operation. It is mostly described and represented in percentage over a year-long period. It can be modelled based on deriving mathematical models or statistical analysis of past data. Also, it can be estimated by calculating the link budget of an FSO communication system. Thus, the availability prediction methods in the present work are based on statistical data and FSO link budget.

The remainder of the paper is organized as follows. In Section 2, availability prediction methods are presented. Results and analysis are discussed in Section 3, while the conclusions are drawn in Section 4.

\section{AVAILABILITY PREDICTION METHODS}

As we mentioned that availability of a terrestrial FSO communication link can be predicted using local weather statistics or FSO link budget. In this section, two methods of availability estimations will be demonstrated as follow:

\subsection{Availability Prediction Using Local Weather Fade Statistics}

Link Availability can be modelled based on statistical analysis of long-term local weather data. The longer period of collecting data, the more accurate the prediction models can be derived. Availability prediction model is varying from one region to another. Each region derives its model which best represent its region and fit with its local weather data.For example, in a tropical climate, rain is the most constant factor that occurs most of the year [10]. Normal haze also be considered as a parameter that influences the optical signal [11]-[12]. For a given fade statistics under tropical climate condition as shown in Figure 2 [12].

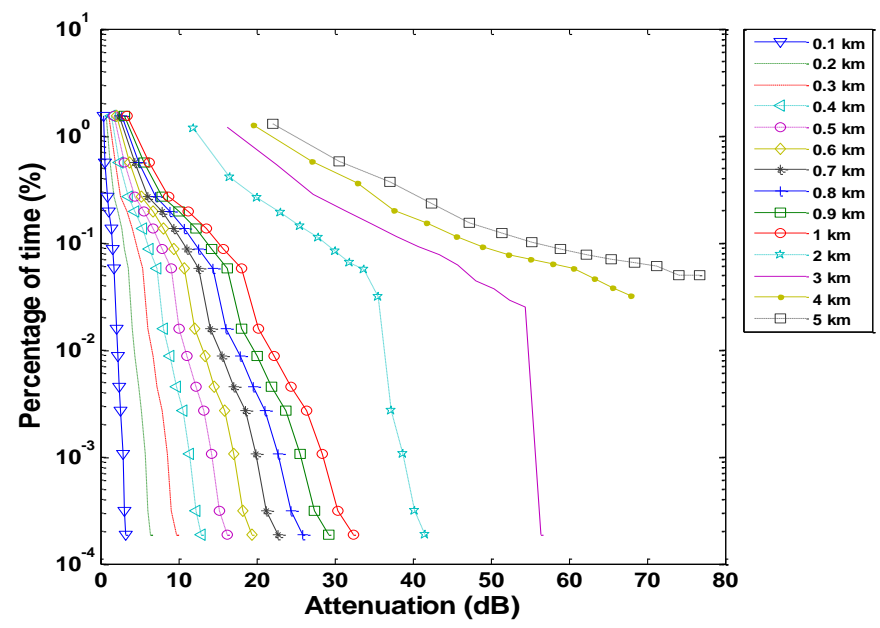

Figure 2. Combined CDF's of predicted attenuation based on average rain rate and visibility data measured in Malaysia over 5 km FSO link 
The availability predition model can be derived and presented as follow [13]:

$$
\begin{aligned}
& P_{\text {out }}(\%)=a \exp (b \cdot|F m|) \\
& a=\left\{\begin{array}{lc}
4.409 & d \leq 1 \mathrm{~km} \\
165.4(d)^{-6.599}+7.85 & 1 \mathrm{~km}<d \leq 5 \mathrm{~km}
\end{array}\right. \\
& b=-0.3147(d)^{-0.9964}
\end{aligned}
$$

where $P_{\text {out }}$ is the outage probability; $a \& b$ are constant coefficients and $F_{m}$ is fade margin (dB).

From above model, link availability $(A)$ for FSO can be predicted as $\left(1-P_{\text {out }}\right)$. This model is developed based on tropical climate. The atmospheric attenuation due to rain and haze were predicted based on the rain rate and visibility data measured in Malaysia. Cumulative distribution function (CDF) of predicted attenuation was obtained using equal probability correlation of CDF of measured data and predicted attenuation models.

\subsection{Availability Prediction Using FSO Link Budget}

The other method which can be used to predit FSO link availability is usin FSO link budget. For a typical terrestrial FSO system install in tropical region, the link budget equation can be presented as follows:

$$
P_{r}=P_{t}-\text { Geometrical loss }- \text { Atmospheric loss - Optical losses }
$$

where $P_{t} \& P_{r}$ are transmit and receive power in (dB), and the Geometrical loss can be obtained as [14]:

$$
\text { Geometricd loss }(d B)=20 \log \frac{d \theta}{D}
$$

where $\theta$ is the divergence angle ( $\mathrm{mrad})$ and $D$ is the diameter of the receiver lens $(\mathrm{m})$. The atmospheric attenuation due to haze can be determined using Beer-Lambert law as follow [15]-[16]:

$$
\tau=\exp (-\sigma d)
$$

where $\sigma\left(\mathrm{km}^{-1}\right)$ is the is the scattering coefficient and obtained based on visibility $V$ data. Whereas, atmospheric attenuation due to rain can be obtained as [17]:

$$
A_{\% p p}(d B)=5.43318 Z\left(\gamma_{R}\right)\left(R_{\% q p}^{-0.377}\right) \exp (-0.102 d)
$$

where $\gamma_{R}$ is the specific rain attenuation $(\mathrm{dB} / \mathrm{km})$ and $R$ is the rain rate $(\mathrm{mm} / \mathrm{hr})$.

Determining all potential losses that may occur during the communication link is an indispensable part of the deployment of FSO system. Geometrical and optical / equipment losses in FSO are considered to be constant losses. Geometrical loss depends on the FSO system parameters and link distance. Regardless the cost efficiency of FSO system, various FSO system parameters will result in different availabilities. At the FSO receiver side, excess power after deducting all constant losses from transmitted power that launched from the transmitter will be considered a link margin. This margin will be allocated for any atmospheric weather influence within the propagating optical link. In other words, the link margin identifies the allowable atmospheric attenuation that is still available. The link margin will be for the additional loss due to rain or haze for optical link. The rise in FSO link distance will increase the total loss. The link availability can be obtained if the received power does not exceed the specific receiver sensitivity for the required link distance. The flow chart of the availability prediction method using FSO link budget is showen in Figure 3. 


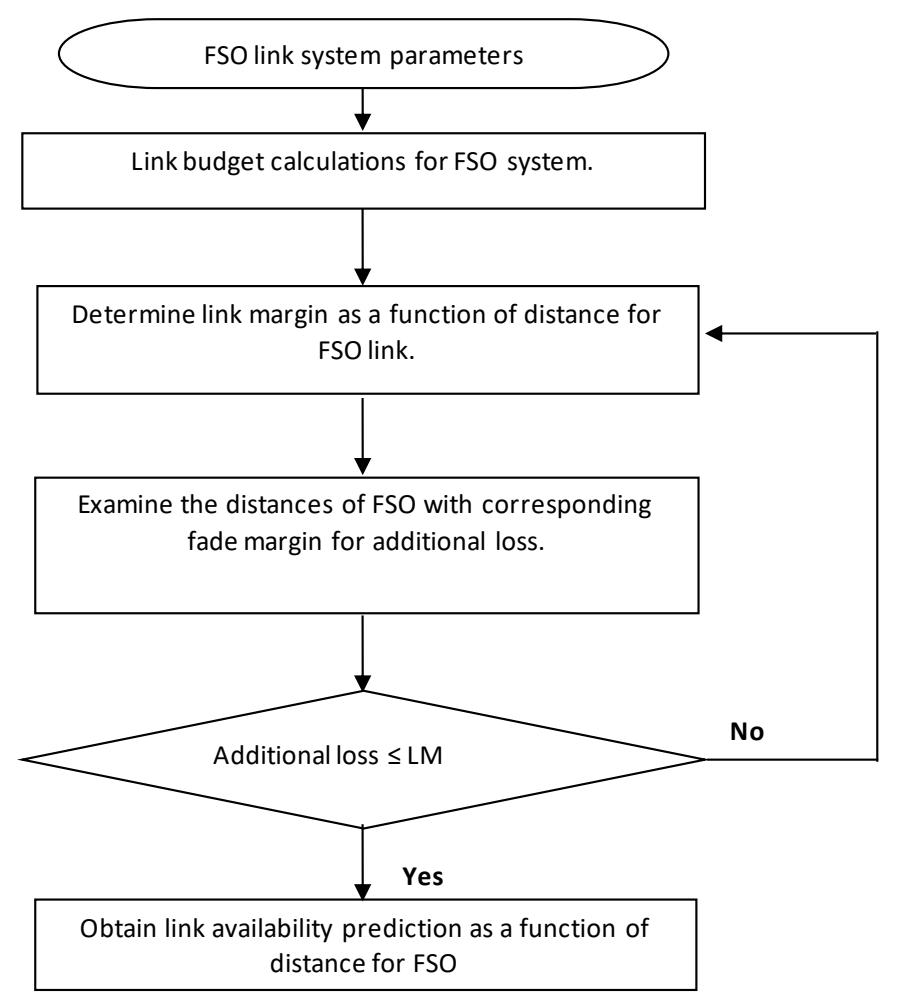

Figure 3. Flow Chart of FSO Availability Prediction Using Link Budget Method

\section{RESULTS AND ANALYSIS}

In this section, the FSO link availability is predicted using the two metods which described early. For a given FSO system parameters the link availability can be calculated and analyzed as follow:

\subsection{Predicted Availability Based on Local Weather Data}

Using (1), FSO link can achieve $98.5 \%$ availability over $3 \mathrm{~km}$ link distance for $15 \mathrm{~dB}$ fade margin that mostly used for FSO commercial system as shown in Figure 4. This availability is still not achieving carrier class availability. Also from Figure 4 it shown that carrier class availability can be only achieve over a link distance of more than 500 meter for the same fade margin. This indicates different FSO system's specifications with higher fade margin will result in higher availability.

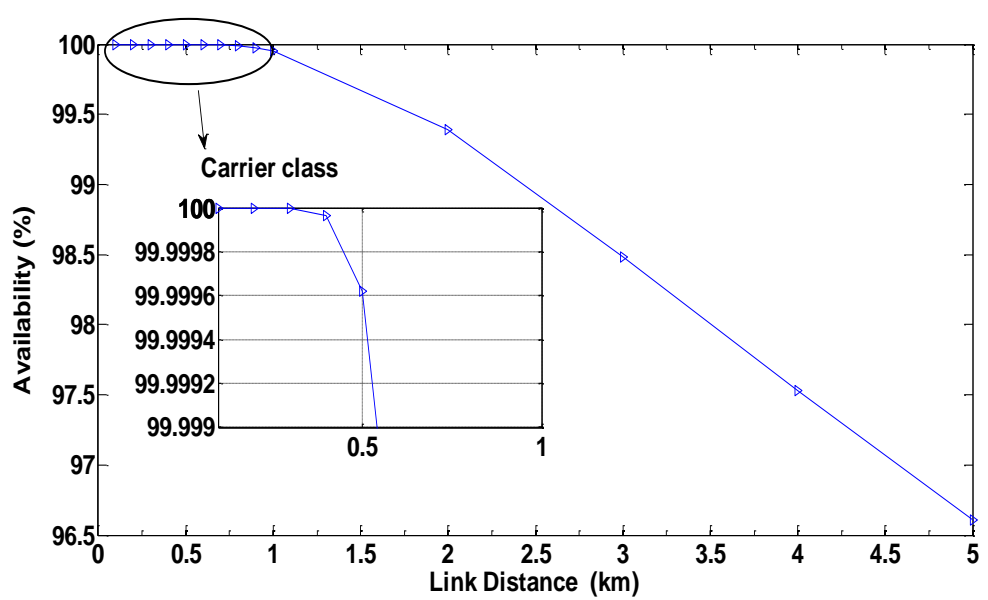

Figure 4. Predicted availability of FSO link under tropical weather condition: Enterprise and Carrier class 


\subsection{Predicted Availability Based on FSO Link Budget}

In tropical region, rain attenuation is assumed to be for the additional loss. The rise in the FSO link distance increases the total loss. The link availability can be obtained if the received optical power does not exceed the specific receiver sensitivity for the required link distance. Availabilities of the FSO link due to rain are calculated by using CDF of the predicted rain attenuation in [10]. Geometrical loss is predicted using (5) for FSO system parameters presented in Table 1; whereas optical loss assumed to be $4 \mathrm{~dB}$.

The link margin is obtained over the variation of the link distances in the ranges from $0.1 \mathrm{~km}$ to 5 $\mathrm{km}$. The exponential relation of fade margin and link distances is depicted in Figure 5.

Table 1. FSO System Specifications

\begin{tabular}{cc}
\hline Items & Specifications \\
\hline Divergence Angle & $2 \mathrm{mrad}$ \\
Transmit Power & $24 \mathrm{~mW}$ \\
Sensitivity & $-45 \mathrm{dBm}$ \\
Wavelength & $850 \mathrm{~nm}$ \\
Tramitter Lens & $2.5 \mathrm{~cm}$ \\
Receiver Lens & $8 \mathrm{~cm}$ \\
\hline
\end{tabular}

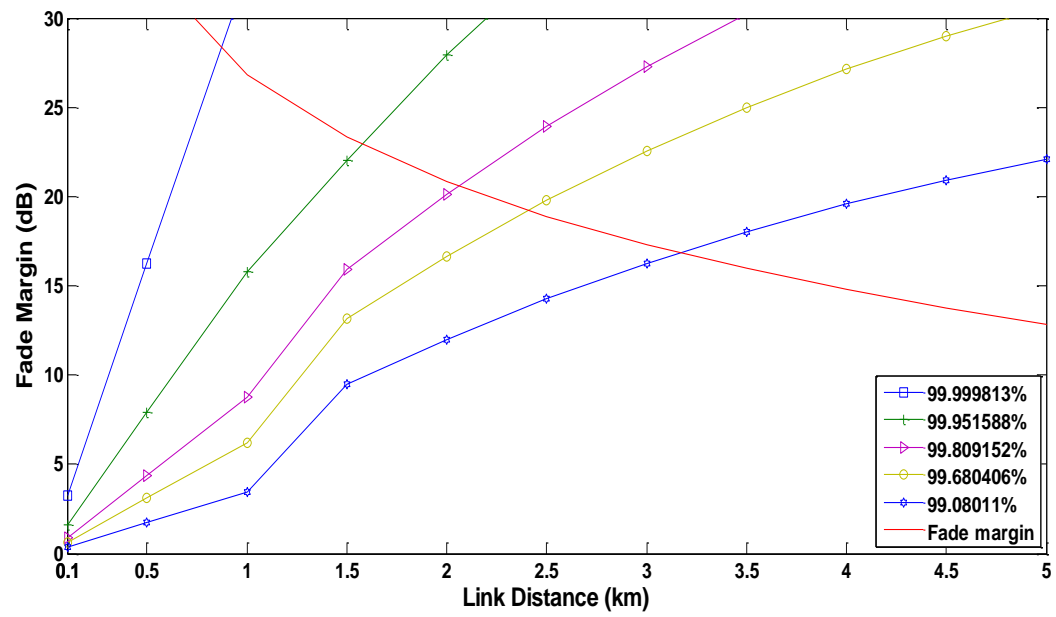

Figure 5. Fade Margin Variations for Different Percentage of Time over FSO Link Distances

The availability curve in Figure 6 is obtained by the corresponding link margin with each FSO attenuation due to rain shown in Figure 5. The availability in Figure 6 provides indications of reasonable link distances for FSO systems in the tropical areas.

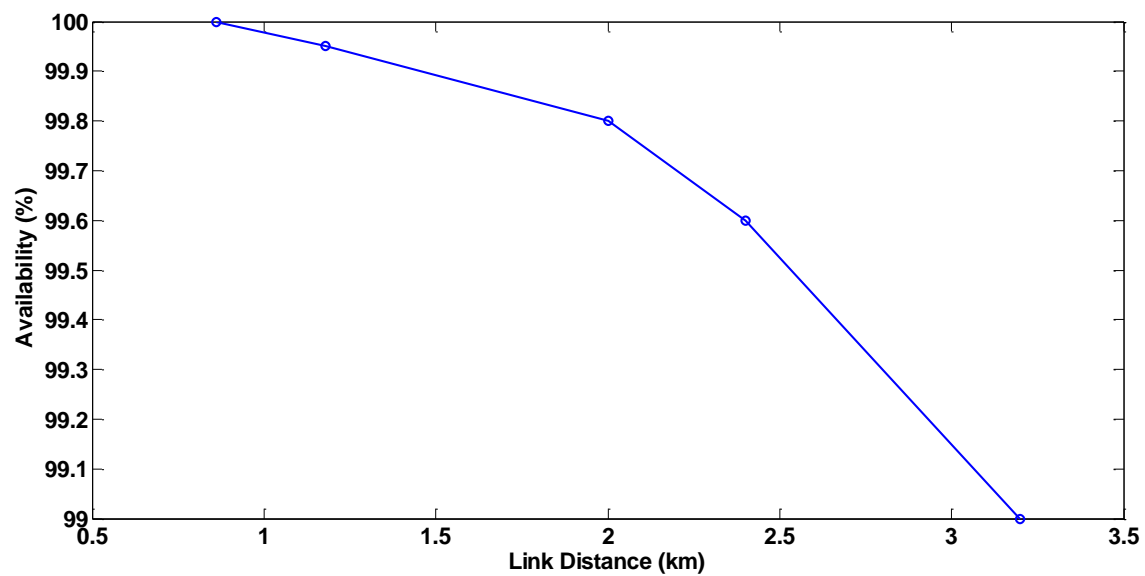

Figure 6. FSO Predicted Availability under tropical weather condition 
Carrier class and enterprise class availability are predicted. These results show that the carrier class 99.999\% (5-nines) availability can be achieved at a maximum distance of 900 meters only. In other words, five nines is equivalent to $0.001 \%$ outage. For this percentage of outage, the amount of potential downtime is equivalent to 5 min per year. Meanwhile, the enterprise availability ( $>99 \%$ ) the FSO can operate of up to three kilometers link distance. This availability corresponds to $1 \%$ outage (three and half day downtime). Thus, the desired availability limits the FSO link range at which the FSO system would be deployed.

\section{CONCLUSION}

This paper demonstrates availability prediction methods for FSO link. The methods are developed based on long-term statistics of local weather data and can be applied to predicted carrier and enterprise availabilities. FSO Link availability can be modelled based on deriving mathematical models or statistical analysis of past data. Also, it can be estimated by calculating the link budget of an FSO communication link. In tropical regions, carrier class availability ( $\geq 99.999 \%$ ) can only be achieved over the range 500 to 900 meters for $15 \mathrm{~dB}$ fade margin; whereas enterprise availability $(<99.999 \%)$ can operate over few kilometers for the same fade margin. The methods can be a useful tool for the design of a terrestrial high-speed, pointto-point, wireless communication links while local weather data are available particular under tropical conditions.

\section{ACKNOWLEDGEMENTS}

Authors are grateful to Research Management Centre, International Islamic University Malaysia to support this research through research grant RIGS16-065-0229.

\section{REFERENCES}

[1] M. A. Khalighi and M. Uysal, "Survey on free space optical communication: A communication theory perspective," Communications Surveys \& Tutorials, IEEE, vol/issue: 16(4), pp. 2231-2258, 2014.

[2] M. N. O. Sadiku and S. M. Musa, "Free space optical communications: An overview," European scientific Journal, vol/issue: 12(9), pp. 55-68, 2016.

[3] F. Nadeem, et al., "Weather effects on hybrid FSO/RF communication link," IEEE J. Sel. Areas in Commun, vol/issue: 27(9), pp. 1687-1697, 2009.

[4] AlQuwaiee, et al., "On the asymptotic capacity of dual-aperture FSO systems with generalized pointing error model," IEEE Transactions on Wireless Communications, vol/issue: 15(9), pp. 6502-6512, 2016.

[5] El-Malek, et al., "Security-reliability trade-off analysis for multiuser SIMO mixed RF/FSO relay networks with opportunistic user scheduling," IEEE Transactions on Wireless Communications, vol/issue: 15(9), 2016.

[6] M. Yahya, et al., "Low cost hybrid RF-FSO to reduce rain effect in tropical region," in Proceedings of IEEE International Conference on RF and Microwave (RFM). Seremban, Malaysia, pp. 250-253, 2011.

[7] Yang, et al., "Performance analysis of free-space optical communication systems with multiuser diversity over atmospheric turbulence channels," IEEE Photonics Journal, vol/issue: 6(2), pp. 1-17, 2014.

[8] Chaouki B. I., et al., "A Generic Simulation Approach for the Fast and Accurate Estimation of the Outage Probability of Single Hop and Multihop FSO Links Subject to Generalized Pointing Errors," IEEE Transactions on Wireless Communications, vol/issue: 16(10), pp. 6822-6837, 2017.

[9] H. Willebrand and B. S. Ghuman, "Free space optics: enabling optical connectivity in today's networks," First Edition. Indianapolis, Indiana, USA: Sams, 2002.

[10] A. Basahel, et al., "Availability Assessment of Free-Space-Optics Links with Rain Data From Tropical Climates," Journal of Lightwave Technology, vol/issue: 35(19), pp. 4282-4288, 2017.

[11] A. Basahel, et al., "Visibility effect on the availability of a terrestrial free space optics link under a tropical climate," Journal of Atmospheric and Solar-Terrestrial Physics, vol. 143, pp. 47-52, 2016.

[12] A. Basahel, et al., "Availability analysis of free-space-optical links based on rain rate and visibility statistics from tropical a climate," Optik-International Journal for Light and Electron Optics, vol/issue: 127(22), 2016.

[13] A. Basahel, et al., "Availability Modeling of Terrestrial Free-Space-Optical Links Using Fade Statistics from tropical Climate," 4th IEEE International Conference on Smart Instrumentation, Measurement and Applications (ICSIMA). Kuala Lumpur, Malaysia, 2017.

[14] A. Basahel and W. Al-Khateeb, "Carrier Class Availability Prediction for Hybrid FSO/RF System in Heavy Rainfall Regions Based on ITU-R Models," International Journal of Computer and Communication Engineering, vol/issue: 3(6), pp. 404-407, 2014.

[15] H. Weichel, "Laser beam propagation in the atmosphere," Volume TT3. Washington, USA: SPIE press, 1990.

[16] I. I. Kim, et al., "Comparison of laser beam propagation at $785 \mathrm{~nm}$ and $1550 \mathrm{~nm}$ in fog and haze for optical wireless communications," in Proc. SPIE, vol. 4214, pp. 26-37, 2001.

[17] A. Basahel, et al., "A proposed rain attenuation prediction method for free space optical link based on rain rate statistics," ARPN Journal of Engineering and Applied Sciences, vol/issue: 10(23), pp. 17351-17355, 2015. 